\title{
Cystodienoic acid: a new diterpene isolated from the myxobacterium Cystobacter sp.
}

\author{
Ritesh Raju${ }^{1}$, Kathrin I Mohr ${ }^{1,2}$, Steffen Bernecker ${ }^{2}$, Jennifer Herrmann ${ }^{1}$ and Rolf Müller ${ }^{1}$ \\ The Journal of Antibiotics (2015) 68, 473-475; doi:10.1038/ja.2015.8; published online 18 February 2015
}

\section{DESCRIPTION}

Myxobacteria are Gram-negative bacteria that are sources of a large number of compounds with unique structures that possess varying biological activities. They are known to produce secondary metabolites that have more novel structures with those produced by other microbes such as, actinomycetes and fungi. In our search for novel secondary metabolites, Cystobacter ferrugineus strain Cbfe23, which was isolated from a soil sample in China, garnered our attention based on our in-house LC-MS analysis. Specifically, a peak identified with an $\mathrm{m} / \mathrm{z}$ of 352 did not produce any hits in our mass spectral library of compounds, prompting us to further investigate the strain in detail in order to determine the structural profile of the unknown metabolite.

\section{Isolation and fermentation of strain Cbfe23}

Strain Cbfe23 was isolated from a soil sample collected in 1982 in China according to the methods of Reichenbach and Dworkin. ${ }^{1}$ The strain was deposited at the German Collection of Microorganisms (DSM) in Braunschweig (DSM 52764).

The fermentation of Cbfe23 was conducted in a 100-1 fermenter with 70 liters of medium E (skimmed milk $0.4 \%$, soy flour defatted $0.4 \%$, yeast extract $0.2 \%$, starch $1.0 \%, \mathrm{MgSO}_{4} \cdot 7 \mathrm{H}_{2} \mathrm{O} 0.1 \%$, Fe-EDTA $8 \mathrm{mgl}^{-1}$, glycerin $0.5 \%$ ) for $96 \mathrm{~h}$ at $30^{\circ} \mathrm{C}$. The $\mathrm{pH}$ was adjusted to 7.4 with potassium hydroxide (5.0\%) and sulfuric acid (5.0\%). The broth was stirred at $100 \mathrm{rpm}$ and aerated with $0.05 \%$ v.v.m. by submersed fumigation for the first $20 \mathrm{~h}$ and then increased to $0.1 \%$ v.v.m. until the end of the process. The dissolved oxygen content within the fermentation broth was regulated by the stirrer speed to $20 \% \mathrm{pO}_{2}$. Adsorber resin $(3 \%)$ was added to the fermentation broth to bind the cystodienoic acid. The fermenter was inoculated with 31 of a 3-day old preculture (same medium plus 50 mм HEPES).

\section{Isolation of cystodienoic acid}

The XAD resin was filtered from the fermented broth and washed twice with distilled water followed by extraction with methanol (4 $1 \times 2)$. The $\mathrm{MeOH}$ extract was then dried in vacuo, which yielded a crude extract of $(3.6 \mathrm{~g})$. A portion of this crude extract $(1 \mathrm{~g})$ was then partitioned between $250 \mathrm{ml}$ of hexane, $\mathrm{CH}_{2} \mathrm{Cl}_{2}$ and $\mathrm{MeOH}$ to give
157.9, 457.9 and $352.5 \mathrm{mg}$ fractions, respectively. The $\mathrm{MeOH}$ fraction was subsequently purified by semipreparative reverse phase HPLC to yield the UV absorbing compound $1\left(\lambda_{\max } 230 \mathrm{~nm}, t_{\mathrm{R}}=20.7 \mathrm{~min}\right.$; $8.2 \mathrm{mg})$.

A detailed account of the spectroscopic analysis leading to the identification of cystodienoic acid (1) is presented below.

HRESI(+)MS analysis of $\mathbf{1}$ revealed a pseudomolecular ion $\left([\mathrm{M}+\mathrm{H}]^{+}\right)$indicative of a molecular formula $\left(\mathrm{C}_{20} \mathrm{H}_{32} \mathrm{O}_{5}\right)$ with five double bond equivalents (DBEs). A detailed examination of the NMR (methanol- $d_{4}$ ) data (Table 1; see Supplementary Figures S1-S3) revealed four $\mathrm{sp}^{2}$ carbon resonances $\left(\delta_{\mathrm{C}}\right.$ 116.4-162.1) and two carbonyls $\left(\delta_{\mathrm{C}} 170.1 / 171.5\right)$, accounting for four DBEs with the requirement that $\mathbf{1}$ be monocyclic. COSY correlations suggested two isolated spin systems, with the first system between methylene $\mathrm{H}_{2}-4$ $\left(\delta_{\mathrm{H}} 2.38,2.21\right)$ and the olefinic methine $\mathrm{H}-3\left(\delta_{\mathrm{H}} 6.92\right)$. The second system was suggested to start between methylene $\mathrm{H}_{2}-6\left(\delta_{\mathrm{H}} 1.40,1.48\right)$ and a second methylene, $\mathrm{H}_{2}-7\left(\delta_{\mathrm{H}} 1.47,1.76\right)$, across two methines, H-8 $\left(\delta_{\mathrm{H}} 1.79\right)$ and $\mathrm{H}-9\left(\delta_{\mathrm{H}} 1.60\right)$ and to terminate at two sets of methylenes, $\mathrm{H}_{2}-10\left(\delta_{\mathrm{H}} 1.59-1.74\right)$ and $\mathrm{H}-11\left(\delta_{\mathrm{H}} 2.29\right)$, which thereby led to the sequence from C-6 to C-11 (Figure 1). Owing to an overlap of correlations in the COSY spectrum for the second isolated spin system, HMBC correlations were used to further corroborate this sequence. $\mathrm{HMBC}$ correlations from the olefinic methyl $\mathrm{H}_{3}-15$ $\left(\delta_{\mathrm{H}} 1.83\right)$ to the carbonyl C-1 $\left(\delta_{\mathrm{C}} 171.5\right)$, quaternary carbon C-2 $\left(\delta_{\mathrm{C}} 129.8\right)$ and C-3 $\left(\delta_{\mathrm{C}} 141.3\right)$ led to the extension of the first isolated spin system. Similarly, HMBC correlations from the second olefinic methyl $\mathrm{H}_{3}-19\left(\delta_{\mathrm{C}} 2.15\right)$ to $\mathrm{C}-11\left(\delta_{\mathrm{C}} 42.0\right), \mathrm{C}-12\left(\delta_{\mathrm{C}} 162.1\right), \mathrm{C}-13$ $\left(\delta_{\mathrm{C}} 116.4\right)$ and $\mathrm{C}-14\left(\delta_{\mathrm{C}} 170.1\right)$ extended the second isolated spin system. The connectivity of the two extended isolated spin systems was established by reasonable $\mathrm{HMBC}$ correlations from $\mathrm{H}_{2}-4$ to C-5 $\left(\delta_{\mathrm{C}} 46.9\right), \mathrm{C}-6\left(\delta_{\mathrm{C}} 40.4\right)$ and C-20 $\left(\delta_{\mathrm{C}} 21.4\right)$ through a quaternary carbon C-5 flanked by the pendant methyl $\mathrm{H}_{3}-20\left(\delta_{\mathrm{H}} 0.97\right)$, which also showed correlations to C-4,C-5, C-6 and C-9. Further HMBC correlations from the methylene $\mathrm{H}_{2}-4$ to $\mathrm{C}-9$ and from $\mathrm{H}-9$ to C-4 suggested the presence of a cyclopentane unit (C-5 to C-9; Figure 1). Moreover, $\mathrm{HMBC}$ correlations from the tertiary methyls $\mathrm{H}_{3}-17$ $\left(\delta_{\mathrm{H}} 1.20 / \delta_{\mathrm{C}} 29.5\right)$ and $\mathrm{H}_{3}-18\left(\delta_{\mathrm{H}} 1.16 / \delta_{\mathrm{C}} 26.4\right)$ to one another and

${ }^{1}$ German Centre for Infection Research Association, Braunschweig, Germany and ${ }^{2}$ Department of Microbial Drugs, Helmholtz Centre for Infection Research, Braunschweig, Germany

Correspondence: Professor R Müller, German Centre for Infection Research Association, Inhoffenstrasse 7, Braunschweig 38124, Germany.

E-mail: rom@mx.uni-saarland.de

Received 5 August 2014; revised 18 December 2014; accepted 9 January 2015; published online 18 February 2015 
Table 1 NMR (500 MHz, $\mathrm{CD}_{3} \mathrm{OD}$ ) data for (1)

\begin{tabular}{|c|c|c|c|c|c|}
\hline Position & $\delta_{H}$, mult $(\mathrm{J}$ in $\mathrm{Hz})(\mathbf{1})$ & $\delta_{C^{a}}$ & $\cos Y$ & $H M B C$ & ROESY \\
\hline 1 & & 171.5 & & & \\
\hline 2 & & 129.8 & & & \\
\hline 3 & $6.92, t(7.8)$ & 141.4 & $4 \mathrm{a} / \mathrm{b}$ & $1,2,4,5,15$ & 20 \\
\hline $4 a$ & $2.38, \mathrm{dd}(14.6,7.8)$ & 41.9 & 3 & $1,2,3,5,6,9,20$ & \\
\hline $4 b$ & $2.21, \mathrm{dd}(14.6,7.8)$ & & 3 & $1,2,3,5,6,9,20$ & \\
\hline 5 & & 46.9 & & & \\
\hline $6 a$ & $1.48^{\mathrm{b}}, \mathrm{m}$ & 40.4 & $6 b, 7 a$ & $5,7,8,9,20$ & \\
\hline $6 b$ & $1.40, \mathrm{~m}$ & & $6 a, 7 a / b$ & $5,7,8,9,20$ & \\
\hline $7 a$ & $1.76, \mathrm{~m}$ & 26.7 & $6 a / b, 7 b$ & 8,16 & \\
\hline $7 b$ & $1.47^{\mathrm{b}}, \mathrm{m}$ & & $6 b, 7 a, 8$ & 8,16 & \\
\hline 8 & $1.79, \mathrm{~m}$ & 57.3 & 7b, 9 & 6 & \\
\hline 9 & $1.60, \mathrm{~m}$ & 49.4 & 8,10 & $4,5,8,10,16,20$ & \\
\hline 10 & $1.59-1.74, \mathrm{~m}$ & 32.3 & 8,11 & & 13 \\
\hline 11 & $2.29, \mathrm{~m}$ & 42 & 10 & $9,10,12,13,19$ & \\
\hline 12 & & 162.1 & & & \\
\hline 13 & $5.67, \mathrm{~s}$ & 116.4 & & $11,12,14,19$ & 13 \\
\hline 14 & & 170.1 & & & \\
\hline 15 & $1.83, \mathrm{~s}$ & 12.8 & & $1,2,3$ & \\
\hline 16 & & 73.9 & & & \\
\hline 17 & $1.20, \mathrm{~s}$ & 29.5 & & $8,16,18$ & \\
\hline 18 & $1.16, \mathrm{~s}$ & 26.4 & & $8,16,17$ & \\
\hline 19 & $2.15, \mathrm{~s}$ & 19.1 & & $11,12,13,14$ & \\
\hline 20 & $0.97, \mathrm{~s}$ & 21.4 & & $4,5,6,9$ & 3 \\
\hline
\end{tabular}

${ }^{a}$ Assignments supported by HSQC and HMBC experiments. boverlapping signals.

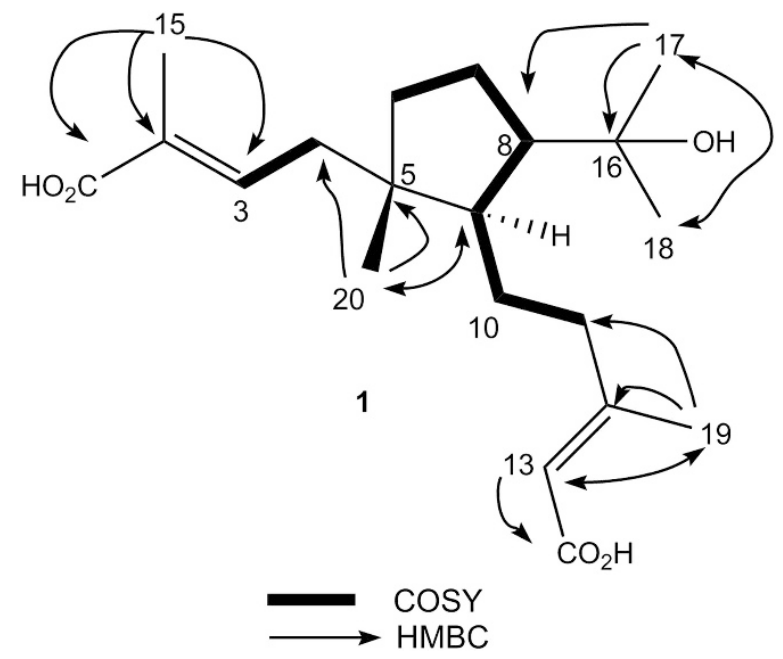

Figure 1 Key 2D NMR correlations for 1 .

to the oxy quaternary carbons $\mathrm{C}-16\left(\delta_{\mathrm{C}} 73.9\right)$ and C-8 $\left(\delta_{\mathrm{C}} 57.3\right)$ confirmed the attachment of a 2-hydroxypropan-2-yl residue to position C-8. Having taken into consideration the DBEs, the carbonyls were identified as a dicarboxylic acid moiety. ROESY correlations between $\mathrm{H}-9$ and $\mathrm{H}-3$ showed that they were on the same plane suggesting that the tertiary methyl $\mathrm{H}_{3}-20$ and $\mathrm{H}-9$ were in a trans orientation, whereas ROESY correlations between $\mathrm{H}-13$ and $\mathrm{H}_{2}-10$ and the ${ }^{13} \mathrm{C}$ chemical shifts for Me-15 and Me-19 indicated that the double bonds had an $E$ configuration.

Cystodienoic acid (1) displayed no significant antimicrobial activity. However, it did display cytotoxic activity against HCT-116 cancer cells with a $\mathrm{GI}_{50}$ of $0.47 \mu \mathrm{g} \mathrm{ml}^{-1}(1.33 \mu \mathrm{M})$. We next carried out chemical

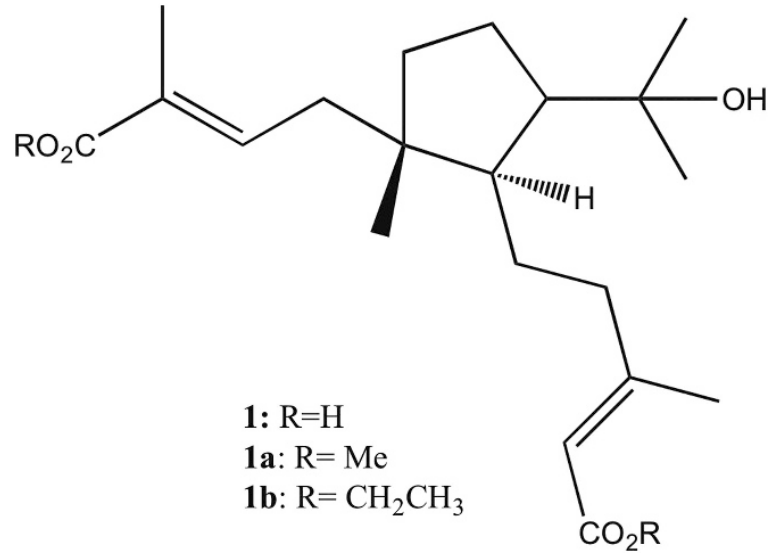

Figure 2 Structures of $1,1 \mathrm{a}$ and $1 \mathrm{~b}$.

modifications on the core structure and generated two derivatives consisting of a di-methyl ester (1a) and a di-ethyl ester (1 b; Figure 2). Unfortunately, the semisynthetic derivatives $\mathbf{1 a}$ and $\mathbf{1 b}$ showed $\mathrm{GI}_{50}$ values of 32.2 and $24.5 \mu \mathrm{M}$, respectively. This result suggests that the carboxylic acid residue in the structure has an essential role in its cytotoxic activity.

The metabolites closest to cystodienoic acid are the dolabellane diterpenoids (Figure 3), which were first isolated from the mollusk Dolabella californica $^{2}$ and were later found in many brown algae mainly belonging to the family Dictoytacea. ${ }^{3,4}$ Octocorals $s^{5,6}$ have also been sources for dolabellane chemistry. Recently, these compounds have also been isolated from terrestrial plants. ${ }^{7}$ The discovery of a similar dolabellane diterpenoid carbon skeleton, cystodienoic acid from the myxobacterium Cystobacter sp. suggests the possibility that these diterpenoids are produced by a microbe, perhaps an as-yet unidentified myxobacterium, mainly owing to the similar chemistry that is observed among a wide variety of marine and terrestrial organisms. The increasing number of observations of similar chemistry occurring in both microbes and marine/terrestrial organisms is rather intriguing and deserves further investigation and understanding of the role of the microbial community within an organism.

\section{EXPERIMENTAL METHODS}

NMR spectra were obtained on a Bruker Ascend $500 \mathrm{MHz}$ spectrometer equipped with a cryoprobe (Bruker Biospin $\mathrm{GmbH}$, Waldbronn, Germany), in the solvents indicated and referenced to residual ${ }^{1} \mathrm{H}$ signals in deuterated solvents. ESI-MS were acquired using an Agilent 1100 Series (Agilent Technologies, Waldbronn, Germany) separations module equipped with an Agilent 1100 Series LC/MSD mass detector in both positive and negative ion modes under the following conditions: Zorbax $\mathrm{C}_{8}$ column, $150 \times 4.6 \mathrm{~mm}$, eluting with $95 \% \mathrm{H}_{2} \mathrm{O} / \mathrm{MeCN}$ to $5 \% \mathrm{H}_{2} \mathrm{O} / \mathrm{MeCN}$ (with isocratic $0.01 \%$ TFA) over $22 \mathrm{~min}$ at $0.4 \mathrm{ml} \mathrm{min}^{-1}$ and then held for $5 \mathrm{~min}$. HRMS was carried out using an UltiMate 3000 rapid separation liquid chromatography system (Dionex RSLC, Thermo Fisher Scientific, Dreieich, Germany) coupled to an UHR-TOF mass spectrometer (Bruker Daltonik MaXis, Bruker Daltonik GmbH, Bremen, Germany) operating in the positive ESI mode.

\section{Biological assay}

Antimicrobial screening. All microorganisms were obtained from the German Collection of Microorganisms and Cell Cultures (Deutsche Sammlung für Mikroorganismen und Zellkulturen, DSMZ), the 

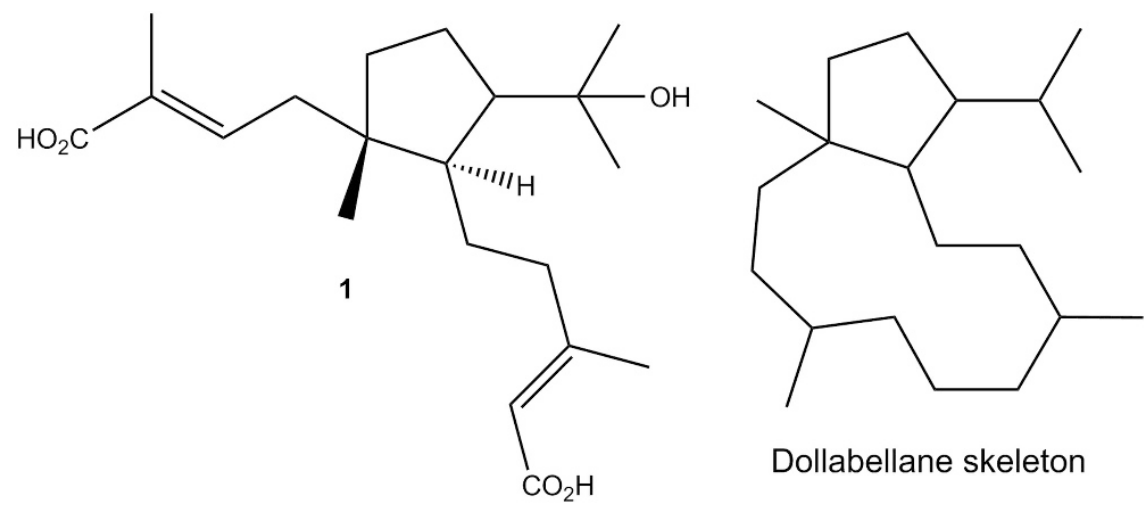

Figure 3 Structure of 1 and the dollabellane carbon skeleton.

American Type Culture Collection (ATCC) or our internal strain collection and were handled according to standard procedures. For microdilution assays overnight cultures of microorganisms were prepared in Myc medium (1\% phytone peptone, $1 \%$ glucose, $50 \mathrm{~mm}$ HEPES, pH 7.0; yeast and fungi), M7H9 medium (Difco Middlebrook 7H9 broth supplemented with BBL Middlebrook ADC enrichment and $2 \mathrm{mll}^{-1}$ glycerol; M. smegmatis) or Mueller-Hinton broth $(0.2 \%$ beef infusion solids, $1.75 \%$ casein hydrolysate, $0.15 \%$ starch, $\mathrm{pH} 7.4$; used for all other bacteria listed). Overnight cultures were diluted in the respective growth medium to achieve a final density of $10^{5}-10^{6}$ cfu $\mathrm{ml}^{-1}$. Serial dilutions of cystodienoic acid and its derivatives were prepared in sterile 96-well plates. After adding the cell suspension to the wells, the microorganisms were grown on a microplate shaker (750 rpm, $\left.30-37^{\circ} \mathrm{C}, 16-48 \mathrm{~h}\right)$. Growth inhibition was assessed by visual inspection. The MIC values presented are the lowest concentration of antibiotic at which there was no visible growth.

Cytotoxicity assay. Human HCT-116 colon carcinoma cells (ACC-581) were obtained from the German Collection of Microorganisms and Cell Cultures (Deutsche Sammlung für Mikroorganismen und Zellkulturen, DSMZ) and were cultured in McCoy's 5A medium supplemented with $10 \% \mathrm{FBS}$ at $37^{\circ} \mathrm{C}$ with $5 \% \mathrm{CO}_{2}$. Cells were seeded at $6 \times 10^{3}$ cells per well in 96-well plates (Corning CellBind, Fisher Scientific, Pittsburgh, PA, USA) in $180 \mu$ l complete medium and were directly treated with the compounds in serial dilution. Treated cells were incubated for 5 days. To assess the viability of the treated cells compared with that of the cells treated with the internal solvent control, $20 \mu \mathrm{l}$ of $5 \mathrm{mg} \mathrm{ml}^{-1}$ MTT (thiazolyl blue tetrazolium bromide) in PBS was added per well and further incubated for $2 \mathrm{~h}$ at $37^{\circ} \mathrm{C}$. The medium was then discarded and cells were washed with PBS (100 $\mu$ l) before adding 2-propanol/10N $\mathrm{HCl}(250: 1, v / v ; 100 \mu \mathrm{l})$ to dissolve the formazan granules. The absorbance at $570 \mathrm{~nm}$ was measured using a microplate reader (Infinite 200 PRO, Perkin Elmer, Tecan, Crailsheim, Germany), and $\mathrm{IC}_{50}$ values were determined by sigmoidal curve fitting.

\section{Cystodienoic acid di-methyl ester (1a)}

Cystodienoic acid $(2.0 \mathrm{mg})$ was dissolved in $0.5 \mathrm{ml}$ of $\mathrm{MeOH}$ and then mixed with $200 \mu \mathrm{l}$ of TMS-diazomethane solution (Sigma-Aldrich). The solution was stirred at room temperature for $\sim 6 \mathrm{~h}$. The reaction mixture was then quenched with $100 \mu$ of acetic acid and dried in vacuo. The reaction mixture was then resuspended in $\mathrm{MeOH}(0.5 \mathrm{ml})$ and subjected to semipreparative HPLC (Zorbax, $\mathrm{C}_{8}$ column,
$250 \times 9.4 \mathrm{~mm}, 5 \mu \mathrm{m}, 3 \mathrm{ml} \mathrm{min}{ }^{-1}, 10-100 \% \mathrm{MeCN} / \mathrm{H}_{2} \mathrm{O}$ gradient over $20 \mathrm{~min}$ to yield $1 \mathrm{a}\left(t_{\mathrm{R}}=17.8 \mathrm{~min}, 1.2 \mathrm{mg}\right)$.

\section{Cystodienoic acid di-ethyl ester (1b)}

Cystodienoic acid $(2.5 \mathrm{mg})$ was dissolved in $1 \mathrm{ml}$ of EtOH and DCC $(0.5 \mathrm{mg})$ and DMAP $(0.2 \mathrm{mg})$ were added and stirred at room temperature for $18 \mathrm{~h}$. The resulting product was passed through a cotton filter, dried in vacuo and then resuspended in $\mathrm{MeOH}(0.5 \mathrm{ml})$. The reaction mixture was subjected to semipreparative HPLC (Zorbax,

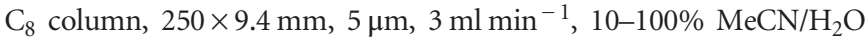
gradient over $20 \mathrm{~min}$ to yield $\mathbf{1 b}\left(t_{\mathrm{R}}=19.5 \mathrm{~min}, 1.0 \mathrm{mg}\right)$.

Cystodienoic acid (1): colorless oil; $[\alpha]_{\mathrm{D}}^{23}+35$ ( c 0.10, MeOH); UV $(\mathrm{MeOH}) \lambda_{\max }(\log \varepsilon) 220 \mathrm{~nm}$ (4.35); NMR data; HRESIMS $\mathrm{m} / \mathrm{z}$ $353.2320[\mathrm{M}+\mathrm{H}]^{+}$(calculated for $\mathrm{C}_{20} \mathrm{H}_{33} \mathrm{O}_{5}$ 353.2328).

Cystodienoic acid di-methyl ester (1a): colorless oil; $[\alpha]_{D}^{23}+30$ (c 0.10, MeOH); UV (MeOH) $\lambda_{\max }(\log \varepsilon) 220 \mathrm{~nm}$ (4.34); NMR data, see Supplementary Table S1; HRESIMS $m / z 381.2636[\mathrm{M}+\mathrm{H}]^{+}$ (calculated for $\mathrm{C}_{22} \mathrm{H}_{37} \mathrm{O}_{5} 381.2642$ ).

Cystodienoic acid di-ethyl ester (1b): colorless oil; $[\alpha]_{D}^{23}+27$ (c 0.10, MeOH); UV (MeOH) $\lambda_{\max }(\log \varepsilon) 220 \mathrm{~nm}$ (4.34); NMR data, see Supplementary Table S1; HRESIMS m/z 409.2947 [M+H] ${ }^{+}$ (calculated for $\mathrm{C}_{24} \mathrm{H}_{41} \mathrm{O}_{5}$ 409.2955).

\section{ACKNOWLEDGEMENTS}

Research in RM's laboratory was supported by grants from the BMBF and the DFG. We thank Viktoria Schmitt (HIPS) for activity screening of the compounds.

1 Reichenbach, H. \& Dworkin, M. The Prokaryotes, the Myxobacteria, 2nd edn 3416-3487 (Springer-Verlag: New York, N. Y., 1992).

2 Ireland, C., Faulkner, D. J., Finer, J. \& Clardy, J. A novel diterpene from Dollabella californica. J. Am. Chem. Soc. 98, 4664-4665 (1976).

3 Amico, V. et al. Diterpenes based on the dolabellane skeleton from Dictyota dichotoma. Tetrahedron 36, 1409-1414 (1980).

4 Tringali, C., Oriente, G., Piatelli, M. \& Nicolosi, G. Structure and conformation of two new dolabellane-based diterpenes from Dictyota sp. J. Nat. Prod. 47, 615-619 (1984).

5 Duh, C.-Y. et al. Cytotoxic dolabellane diterpenes from the Formosan soft coral Clavularia inflata. J. Nat. Prod. 64, 1028-1032 (2001).

6 Iguchi, K., Fukaya, T., Yasumoto, A. \& Watanabe, K. New marine sesquiterpenoids and diterpenoids from the Okinawan soft coral Clavularia koellikeri. J. Nat. Prod. 67, 577-583 (2004).

7 Ramirez, M. C. et al. Structure, conformation and absolute configuration of new antifeedant dolabellanes from Trichilia trifolia. Tetrahedron 56, 5085-5091 (2000). 